\title{
Políticas de distribuição de renda e os indicadores de desenvolvimento do município de Goiatuba-GO
}

\author{
André Luis dos Santos Carvalho ${ }^{1}$ \\ Lourival da Cruz Galvão Júnior ${ }^{2}$ \\ Edson Trajano Vieira ${ }^{3}$ \\ Moacir José dos Santos ${ }^{4}$
}

\begin{abstract}
Resumo
O objetivo do presente estudo foi investigar como políticas públicas de distribuição de renda contribuem para a melhoria dos indicadores de desenvolvimento do município de Goiatuba (GO), com ênfase ao Benefício de Prestação continuada (BPC) e ao Programa Bolsa Família (PBF). A pesquisa caracteriza-se, quanto à abordagem do problema, como qualitativa do tipo documental e bibliográfica; e quanto aos objetivos, como descritiva e exploratória. O tratamento de dados realizou-se mediante análise documental, buscando comparar os dados coletados no período anterior ao Bolsa Família, de 2000 a 2003, ao período de plena execução do Programa, de 2004 a 2010. A pesquisa demonstrou que o Índice de Desenvolvimento Humano (IDHM) do município de Goiatuba (GO) passou de 0,628 em 2000 para 0,725 em 2010, com um grande avanço em todas as dimensões que o compõem. Demonstrou ainda que, no mesmo período, houve um aumento na quantidade de famílias de Goiatuba (GO) inscritas no Cadastro Único para Programas Sociais, uma evolução também no valor médio mensal de benefícios por família e ainda no valor total repassado pelo programa Bolsa Família ao município de Goiatuba (GO), saindo da casa dos R\$ 50.000 em 2004 para superar R\$ 150.000,00 em 2010. Esse cenário de evolução das políticas públicas de distribuição direta de renda possivelmente contribuiu para o avanço em todas as dimensões que compõem o Índice de Desenvolvimento Humano (IDHM) do Município de Goiatuba (GO).
\end{abstract}

Palavras-chave: Planejamento e Desenvolvimento Regional. Indicadores Socioeconômicos. Políticas Públicas. Distribuição de Renda.

\begin{abstract}
The objective of the present study was to investigate how public income distribution policies contribute to the improvement of the development indicators of the municipality of Goiatuba (GO), with an emphasis on the Benefit of Continued Provision (BPC) and the Bolsa Familia Programme (PBF). The research is characterized, as to the approach of the problem, as qualitative of the documental and bibliographic type and as to the objectives as descriptive and exploratory. The data processing was carried out through documentary analysis, seeking to compare the data collected in the period prior to the Bolsa Familia, from 2000 to 2003, to the period of full implementation of the Program, from 2004 to 2010. The research showed that the Human Development Index (IDHM) municipality of Goiatuba (GO) went from 0.628 in 2000 to 0.725 in 2010, with a great advance in all its dimensions. It also showed that in the same period \footnotetext{
Goiatuba (FESG). andreluisgtba@hotmail.com

${ }^{2}$ Doutor em Ciências da Comunicação (ECA/USP). Professor do Programa de Pós-Graduação em Planejamento e Desenvolvimento Regional da Universidade de Taubaté (UNITAU).galvaojr@uol.com.br

${ }^{3}$ Doutor em História Econômica (USP). Professor do Programa de Pós-Graduação em Planejamento e Desenvolvimento Regional da Universidade de Taubaté (UNITAU). etrajanov@gmail.com

${ }^{4}$ Doutor em História (UNESP). Professor do Programa de Pós-Graduação em Planejamento e Desenvolvimento Regional da Universidade de Taubaté (UNITAU).professormoacirsantos@gmail.com
}

${ }^{1}$ Mestre em Planejamento e Desenvolvimento Regional (UNITAU). Professor da Fundação de Ensino Superior de
\end{abstract}


there was an increase in the number of Goiatuba (GO) families entered in the Single Register for Social Programs, an increase in the average monthly amount of benefits per family and still in the total amount passed by Bolsa Familia Programme to the municipality of Goiatuba (GO), from R\$ 50,000 in 2004 to R\$ 150,000.00 in 2010. This scenario of the evolution of public policies of direct income distribution has possibly contributed to the advance in all the dimensions that make up the Human Development Index (IDHM) of the Municipality of Goiatuba (GO).

Keywords: Planning and Regional Development. Socioeconomic Indicators. Public Policies. Income distribution.

\section{Introdução}

Os programas de transferência de renda, como medidas específicas destinados à população carente, demonstram-se importantes instrumentos para erradicar ou mesmo minimizar em menor prazo os problemas da situação de pobreza, com potencial de combater o ciclo da pobreza transmitido entre as gerações (CACCIAMALI et al., 2010). Nesse contexto, interessa destacar como contribuição no presente estudo dois diferentes meios brasileiros de enfrentamento à pobreza para a inclusão social de pessoas em situação de pobreza, o que pode contribuir com o processo de desenvolvimento regional: o sistema de assistência social, por intermédio do Benefício de Prestação Continuada (BPC); e o Programa Bolsa Família (PBF). Ambas as ações mostram-se pertinentes enquanto programas de transferência de renda ao estabelecerem condicionantes que vinculam o acesso de crianças e de jovens à saúde e a educação como maneira de priorizar o aumento do estoque de capital humano, além de colocarem-se como alternativa para a quebra do ciclo de pobreza e a sua reprodução entre gerações (CACCIAMALI et al., 2010).

A execução de políticas públicas de distribuição de renda para o enfrentamento da pobreza e da extrema pobreza mediante transferência direta de recursos financeiros ao beneficiário, e a sua contribuição para os indicadores de desenvolvimento do município de Goiatuba, estado de Goiás, demonstrou-se um interessante objeto de pesquisa para medir os efeitos do BPC e do PBF no município em relação aos seus efeitos.

A pesquisa subjacente ao presente artigo caracteriza-se, quanto à abordagem do problema, como qualitativa do tipo documental e bibliográfica; e quanto aos objetivos, como descritiva e exploratória, sendo que o tratamento de dados ocorreu mediante análise documental. Deste modo, o presente artigo pretende compreender a representatividade das políticas de distribuição de renda nos indicadores de desenvolvimento do município de Goiatuba (GO). O objetivo norteador do artigo é a investigação de como as políticas públicas de distribuição 
de renda contribuem para os indicadores de desenvolvimento do município de Goiatuba (GO). Denota-se que as políticas públicas, inclusive às destinadas a promoção da inclusão social, têm efeitos sobre o território e o desenvolvimento local, daí a particularização do estudo em relação à população de Goiatuba (GO). O artigo divide-se em 5 seções: a primeira, a introdução; a segunda, a discussão dos conceitos e abordagens sobre as políticas públicas dedicadas ao desenvolvimento; a terceira, a caracterização das políticas públicas relacionadas à distribuição de renda enquanto; a quarta, a apresentação dos resultados; e a última, a análise sucedida pelas considerações finais.

\section{Desenvolvimento e Territorialidade}

As estruturas nacionais de deliberação referentes ao espaço pátrio demonstram-se, de forma generalizada, debilitadas. A situação decorre do crescimento constante e universalizado das cadeias econômicas, financeiras e tecnológicas inseridas em cenários onde a temática do desenvolvimento demonstra-se estratégica para inclusão dos países na economia mundial (BRANDÃO, 2007). Para Dallabrida (2014), no âmbito do debate conceitual referente ao desenvolvimento destaca-se o território, definido como a parcela de um determinado lugar que, ao longo do tempo, vai se edificando a partir de interações de natureza social, econômica e institucional entre aqueles que operam no respectivo local, como o Estado, as instituições, as organizações sociais ou corporativas e os indivíduos.

Abramovay (2010) defende que, a partir da conceituação do território, tendo como premissa a investigação dos vínculos entre os atores sociais para a constituição de estruturas produtivas locais, houve o favorecimento significativo dos estudos do meio rural que passou a ser compreendido não só pelo desenvolvimento da agricultura, mas também pela forma como esse setor interage com os atores sociais. De acordo com Santos (2006), na caracterização do território é preciso que seja estabelecida uma forma que compreenda a junção dos recursos naturais que existem originariamente em um determinado lugar, que pode referir-se a uma área maior, como um país, ou mesmo a uma área menor, regional ou local, com tudo o que ali for adicionado com a ação humana.

Brandão (2007) cita que a concretização do desenvolvimento depende do papel assumido pelo Estado e também pelas demais pessoas que integram ou que de alguma forma estejam envolvidas no contexto da região nos diferentes campos, como o social, o econômico, o 
ambiental e o cultural, devendo ainda existir interação coerente entre a participação de todos os interessados. Conforme Dallabrida (2014), a discussão em torno do tema "desenvolvimento territorial" implica na investigação da estrutura de governança territorial do modelo de desenvolvimento ao qual atores sociais locais estão vinculados. Segundo Abramovay (2010), a ideia de território contribui para a compreensão mais ampla do meio rural, fazendo com que os agricultores não sejam vistos como únicos atores e, sim, como indivíduos membros de um contexto social maior, do mesmo modo que a atividade agrícola também não seja vista como singular, mas como uma parcela de um contexto produtivo maior.

Santos (2006), ao caracterizar território, descreve que sua existência é oriunda da composição material, portanto diferente do espaço que o compreende, além de todo o seu sistema material e de vida que o acalora. A caracterização do território compreende, então, uma essência material que lhe pertence, embora a vida social ou real dependa da interação social. Brandão (2007), por sua vez, critica o fato de existir uma tendência mundial que vê o desenvolvimento projetado em uma escala espacial menor como o mais apropriado. Essa corrente baseia-se no argumento de que uma linha espacial menor favorece a construção de um processo adequado para realizar o desenvolvimento sustentável e condiz com um conjunto de forças de cunho social e político denominado território. Dallabrida (2014) afirma que o aspecto territorial do desenvolvimento é importante e tem como destaque a análise das ações de organizações voltadas à expansão da atividade econômica de forma cooperada, ressaltando que essas estruturas permitem compreender e valorizar a textura social da localidade.

Abramovay (2010) destaca que os trabalhos de conceituação teórica quanto à ideia de território facilitam a compreensão da noção de desenvolvimento, para reforçar a diferença entre a figura do processo de desenvolvimento e a figura do crescimento econômico, com valorização das noções de territorialidade para as estruturas pertinentes ao desenvolvimento. Já Dallabrida (2014) destaca que as expectativas para a execução prática do desenvolvimento territorial consistem ao mesmo tempo em circunstâncias desafiadoras e pondera que a eficácia desse desenvolvimento depende de três fatores: participação ativa da sociedade; ações do Estado para suprir as carências locais e combater os obstáculos; e a criação de uma estrutura própria de planejamento do desenvolvimento.

Debates conceituais referentes à dimensão espacial do desenvolvimento contribuem para compreensão dos dados obtidos na condução da pesquisa quanto a ponderação dos desdobramentos territoriais das políticas públicas, de distribuição de renda no Brasil, 
reconhecidas como políticas de escala nacional e, nesse mesmo cenário, a situação dos indicadores socioeconômicos do município de Goiatuba (GO).

Brandão (2011) lembra que, nos últimos anos, o Brasil foi marcado por grandes e complexos projetos voltados ao crescimento, como o PAC - Programa de Aceleração do Crescimento, que revelaram objetivos genéricos para estimular a força produtiva dos sistemas econômicos regionais e, com isso, impulsionar o crescimento de regiões mais retraídas. De acordo com o autor, essas políticas, quando não inseridas em um processo constante de planejamento territorial, não conseguem sequer desempenhar seus objetivos.

Segundo Buarque (2006), o desenvolvimento pode ser definido como um exercício de esforços realizado em um contexto espacial com aptidão para aumentar a viabilidade econômica, as oportunidades sociais e a qualidade de vida das pessoas que integram a comunidade. Dallabrida (2013) entende, por sua vez, que o crescimento econômico não pode ser o único foco das preocupações, devendo ser dada especial atenção ao desenvolvimento regional pelo fato de que este não se dá somente com a variação de indicadores econômicos, exigindo que as ações produtivas superem a dimensão econômica para cumprir com outras variáveis do desenvolvimento.

Oliveira e Lima (2003) apontam que o desenvolvimento local se conecta a um complexo processo de transformação social, envolvendo a participação dos seus sujeitos locais, a ocupação territorial e a evolução no cenário político, na economia e nas relações humanas. $O$ mencionado processo de transformação deve proporcionar a melhor distribuição do resultado obtido entre toda a sociedade, atendendo as mais diferentes necessidades humanas. Vieira e Santos (2012) destacam que a tarefa de definir um significado ou uma conceituação para o desenvolvimento deve se pautar nos valores estabelecidos no contexto histórico de cada sociedade, devendo ainda manter em seu particular a busca por um melhor estilo de vida ao qual a maioria da população tenha acesso. Essa ideia de desenvolvimento se opõe à ideia de progresso econômico, que tem o foco na ampliação da produtividade para oferta de bens e serviços. De acordo com Brandão (2011), a criação de projetos voltados meramente ao crescimento econômico encontra barreiras para serem transformados em um projeto nacional e latino-americano de desenvolvimento e planejamento territorial. Isso ocorre porque essas empreitadas limitam-se ao fornecimento de apoio infraestrutural e suporte para maior aceleração e eficiência nas ações destinadas à exploração de recursos naturais. 
Para Sen (2010), a efetivação do desenvolvimento está diretamente ligada ao tipo de liberdade oferecido as pessoas. Nesse sentido, o autor assevera que, para possibilitar o desenvolvimento, é indispensável que previamente sejam removidas as principais fontes de privação da liberdade, como a situação de pobreza, a intervenção exagerada do Estado, a opressão, a má prestação dos serviços públicos, o aniquilamento social e a falta de oportunidades econômicas. De acordo com Vieira e Santos (2012), no debate entre os historiadores es economistas, a maior parte dos economistas defende o modelo da economia clássica, de modo a medir o desenvolvimento de uma determinada sociedade de acordo com sua aptidão para produção de bens e serviços. Porém, os historiadores defendem um processo que envolva, juntamente com a questão econômica, demandas culturais, sociais e até mesmo psicológicas das pessoas. Segundo Dallabrida (2013), no âmbito do desenvolvimento, a melhoria nas condições de vida da população envolve a efetivação de benefícios para os indivíduos em vários quesitos, como a renda, o poder aquisitivo, as condições de moradia, o lazer, a saúde e as oportunidades de inclusão no mercado de trabalho e de capacitação.

Vieira e Santos (2012) avaliam que o estudo do processo de desenvolvimento deve ultrapassar a dimensão econômica para observar questões sociais voltadas às necessidades humanas, que são complexas e diversificadas como as próprias diferenças regionais, razão pela qual há uma dificuldade em estabelecer um método que seja eficaz para quantificar o desenvolvimento. Para os autores, a política de desenvolvimento regional deve buscar mais do que valores econômicos para cooperar com a melhoria da qualidade de vida dos indivíduos, com investimentos voltados à produtividade social e à valorização das relações culturais e sociais.

Dallabrida (2013) analisa que uma melhor qualidade de vida também pressupõe dar à população a chance de gozar das vantagens de um meio ambiente saudável. Ele assevera, ainda, que muitas das condições desfavoráveis a uma melhor qualidade de vida em âmbito mundial decorreram de uma conduta recursiva praticada por empresas no século $\mathrm{XX}$, que fizeram parte de uma economia voltada ao crescimento a qualquer custo, baseada apenas na promoção financeira.

Vieira e Santos (2012) citam que a reflexão quanto às demandas conceituais do desenvolvimento econômico possibilita a construção de um novo padrão de desenvolvimento capaz de aliar a ampliação da produtividade de bens e serviços com a ampliação da destinação e distribuição, de forma que possam superar a dimensão econômica para contribuir também com 
a melhoria da qualidade de vida dos indivíduos. Trata-se de uma combinação capaz de enfrentar os problemas de ordem social.

\section{Contribuições das políticas de distribuição de renda para o desenvolvimento local}

O Brasil possui um território marcado por um processo desordenado de ocupação, com centralização em determinadas regiões que compõem a maior parte do alicerce produtivo nacional. Tal condição sinaliza que as transformações ocorridas nesse caminho resultaram em uma estruturação regional de absoluta disparidade no tocante às desigualdades sociais e regionais (GRANITO et al 2007). A intervenção do Estado na promoção do desenvolvimento regional com a instituição de políticas públicas surgiu calcada na tese de que o mercado, sozinho, não é capaz de solucionar os problemas decorrentes das desigualdades regionais, ficando assim a ideia de que somente com a mencionada intervenção seria alcançado o desenvolvimento com estabilidade social e econômica (COSTA E CUNHA, 2002).

No início do século passado, as ações governamentais ligadas ao desenvolvimento regional eram executadas a partir de finalidades específicas, sendo previamente constituídas (FERREIRA, 2002). Essas iniciativas eram basicamente destinadas, por exemplo, ao combate dos problemas decorrentes das secas na região do Nordeste ou à ocupação, aproveitamento e aumento das condições econômicas da região da Amazônia. Segundo Costa e Cunha (2002), entre meados do século XX até o final dos anos 1970, os esforços governamentais passaram a se dedicar à promoção do crescimento da indústria do Norte e Nordeste, bem como da agroindústria no Centro-oeste, tendo como base a reestruturação logística e energética, assim como a oferta de incentivo fiscal e financeiro.

Ferreira (2002) anota que, no período compreendido entre os anos 1950 e 1970, em decorrência das mencionadas políticas governamentais voltadas ao financiamento para a modernização da infraestrutura, houve a criação de várias instituições de fomento, como é o caso do Banco do Nordeste. Mas, a partir do mencionado período, com o aumento expressivo da dívida pública, essas políticas declinaram. Costa e Cunha (2002) relatam que, entre os anos 1980 e 1990, o declínio do modelo de política intervencionista, somado à crise mundial do sistema capitalista que sofreu transformações com os efeitos da globalização, gerou uma forte elevação da crise do modelo de desenvolvimento brasileiro que, até então, contava com o Estado como o responsável por instituir programas e demais medidas políticas para garantir o desenvolvimento. 
Ferreira (2002), por sua vez, destaca que o modelo de desenvolvimento regional brasileiro, cuja responsabilidade de gestão e de funcionamento era atribuída ao Estado, chegou ao fim. O autor aponta que isso ocorreu principalmente em razão das novas tendências vindas do avanço da globalização que trouxe, como ênfase, o desenvolvimento sustentável no âmbito econômico e ambiental, bem como a valorização da cidadania e da cooperação.

Segundo Paes e Siqueira (2008), mesmo depois de um período de cinco décadas de políticas públicas destinadas à promoção do desenvolvimento regional e a diminuição da heterogeneidade entre os estados, a desigualdade persiste até os dias atuais, principalmente pela disparidade entre os diferentes locais no que se refere à disponibilidade de recursos financeiros, capital humano e infraestrutura. No campo específico da distribuição de renda, Medeiros et al (2007) registram que, nos últimos anos, o Brasil foi marcado pela ampliação das políticas de transferência de renda para o enfrentamento da pobreza. Os programas são caracterizados pelo repasse dos recursos diretamente aos beneficiados, sendo nesse cenário os mais significativos o Benefício da Prestação Continuada (BPC) e o Programa Bolsa Família (PBF). Os programas de transferência direta de renda como medidas próprias destinadas ao atendimento da população em situação de miserabilidade apresentam-se como instrumentos para erradicação ou mesmo minimização, em menor prazo, dos problemas relacionados à miséria, podendo ter ainda a capacidade de quebrar o ciclo da pobreza e impedir que ela seja transmitida entre as gerações (CACCIAMALI et al., 2010).

O BPC corresponde a um benefício mensal no valor de um salário mínimo vigente no país, pago por transferência direta dos valores ao beneficiário em duas situações: à pessoa idosa, assim considerada aquela com mais de 65 anos; e à pessoa com deficiência severa. Nas duas situações, a renda familiar por pessoa não pode superar um quarto do salário mínimo (MEDEIROS et al, 2007). Cacciamali et al. (2010) relatam que, a partir do final do século XX, houve na maioria dos países preferência pelos programas de proteção social em relação aos programas de seguridade social. Na redução da pobreza, o crescimento econômico sustentável, assim como a estabilidade macroeconômica e a boa governança são fatores preponderantes, porém insuficientes. Segundo Vaitsman et al (2009), a implantação das políticas de transferência de renda no Brasil ocorreu de forma paralela ao trabalho setorial de criação e de prática da política de assistência social, que envolveu um número significativo de atores para esse processo de construção organizado na época a partir de debates, cursos e formação de colegiados. 
O recebimento do BPC é um direito previsto no artigo 203, inciso V da Constituição Federal de 1988, regulamentado pela Lei no 8.742 de 7 de dezembro de 1993 que dispõe sobre a organização da assistência social e dá outras providências, tendo sido colocado em prática a partir de 1995 em um momento em que a gestão da previdência e da assistência social eram feitas de forma conjunta no âmbito do governo federal (MEDEIROS et al, 2007). O BPC desponta como programa nacional de cunho social com a maior dotação orçamentária, correspondendo a 86,21\% do Fundo Nacional da Assistência Social - FNAS (BIN, 2014). Porém, o Bolsa Família ainda se configura como o maior programa social de transferência de renda do Brasil no que se refere à cobertura, que soma 13,5 milhões de famílias beneficiárias, o que corresponde a 50 milhões de pessoas.

Vaitsman et al (2009) destacam que os programas de transferência de renda introduzidos na década de 1990 passaram, a partir de 2003, pela incorporação ao sistema de assistência social em uma direção que deu origem ao Programa Bolsa Família. Contudo, essa construção paralela do Benefício de Prestação Continuada (BPC) demonstra, a partir de 1988, a dupla trajetória do sistema por meio da focalização e do universalismo. De acordo com Cacciamali et al. (2010), o problema é que a seguridade social não apresenta a mesma abertura e amplitude observada nos programas de proteção social, razão pela qual acaba por resultar em maior exclusão pelo não atendimento das inúmeras condições exigidas para o acesso ou manutenção de benefícios, possibilitando a elevação da desigualdade na renda.

Bin (2014) esclarece que o BPC foi visto por muito tempo como um benefício previdenciário e não assistencial, principalmente em razão de sua operacionalização ser feita pelo INSS, o que teria motivado um afastamento de seus objetivos enquanto direitos de proteção social de pessoas em situação de vulnerabilidade. Além disso, a concessão está focada na condição biológica do ser humano, sem considerar a condição biográfica, familiar e social. Bin (2014) também cita que o BPC é o único benefício considerado como um direito de proteção social de natureza não contributiva, efetivado após a Constituição de 1988. Todavia, o benefício encontra-se limitado a critérios, como o da renda mínima familiar e o de comprovação de incapacidade para o trabalho e para vida independente, o que acabou gerando polêmicas quanto ao ajuste de um mecanismo para comprovação da incapacidade.

O Programa Bolsa Família foi criado em 2003 pela Medida Provisória no 132, que foi posteriormente convertida na Lei no 10.836, de 9 de janeiro de 2004. Ele consiste na transferência mensal de renda diretamente aos beneficiários e se originou a partir da unificação 
de vários outros programas sociais existentes até então, espelhando-se no programa Bolsa Escola que também visava estabelecer uma renda mínima (MEDEIROS et al, 2007). A legislação estabelece que criação do Bolsa Família tem por finalidade unificar a gestão e a execução das transferências de renda de outros programas do Governo Federal, destacando-se o Bolsa Escola, o Programa de Alimentação PNNA e o Auxílio-Gás, além do Cadastro Único, conforme disposto do artigo 1ํ, parágrafo único, da Lei no 10.836/2004. A principal característica do Bolsa Família é que o programa se propõe a agir na transferência de renda para o alívio imediato da pobreza; com condicionalidades de acesso à educação, saúde e assistência social; e com ações e demais programas dedicados ao desenvolvimento das famílias, permitindo que os beneficiários superem a situação de vulnerabilidade (MDS, 2015).

Pires e Jardim (2014) informam que o Bolsa Família é um benefício de transferência direta de renda que tem condicionalidades que, embora tenham sido pouco conferidas no início de execução, atualmente são verificadas bimensalmente para a área da educação e, bianualmente, para a área da saúde. Tais condições, na avaliação dos autores, são importantes para o cumprimento do objetivo de quebra do ciclo de pobreza entre as gerações. Cacciamali et al. (2010) entendem que a transferência de renda com condicionalidades permite ao programa enfrentar a reprodução do ciclo de transferência da miséria entre gerações ao oferecer um grau mínimo de renda para o sustento das famílias pobres e garantir oportunidades de acesso à educação e à qualificação, o que resguarda a obtenção de capital humano dos beneficiados. Para Barros et al (2010), constituem objeto de estudo relevante as questões relacionadas com as dificuldades a serem enfrentadas para que seja possível fazer, de modo efetivo, a inclusão social da parcela da população que se encontra em extrema pobreza. Contudo, os autores alertam que, provavelmente, parte da população pode estar tão isolada que não conseguirá ser alcançada nem mesmo pelo cadastro do programa.

De acordo com Zimmermann (2006), a garantia ao direito humano à alimentação e o combate à fome no Brasil se deram efetivamente pelo programa de transferência de renda denominado Bolsa Família, sendo que a proposta do referido programa tem sido amplamente elogiada em nível mundial no âmbito dos meios de comunicação e, também, por cientistas sociais. Barros et al (2010) destacam ainda que o Bolsa Família revela resultados dos quais boa parte se deve ao Cadastro Único, que permitiu a execução do programa de modo descentralizado. Em princípio, o Bolsa Família exigiu maior envolvimento e participação da 
estrutura administrativa municipal e da sociedade civil para formação de forças tarefas voltadas a identificar pessoas em situação de pobreza ou de extrema pobreza.

De acordo com Medeiros et al (2007), a operacionalização do programa envolve diferentes organismos públicos: o gerenciamento é do Ministério do Desenvolvimento Social (MDS); a operacionalização dos pagamentos dos benefícios é da Caixa Econômica Federal (CEF); e a seleção dos beneficiários é dos órgãos municipais de assistência social. Pires e Jardim (2014), ao tratarem sobre a compreensão dos efeitos do Programa Bolsa Família (PBF) nas dinâmicas familiares da pequena cidade de Catingueira, no semiárido nordestino da Paraíba, demonstram mudanças nos perfis entre as gerações que estão relacionadas com o recebimento de uma renda oriunda do mencionado programa, que possibilitou a redução do trabalho infantil, a escolarização de crianças e a ampliação do consumo, sendo essas mudanças nominadas pelos autores como "Geração Bolsa Família".

Pires e Jardim (2014) expõem que na pesquisa de campo realizada em dezembro de 2010 em Catingueira foram entrevistados responsáveis pelo recebimento do benefício, em sua maioria mães de família, sendo que, dentre as perguntas, destacou-se a referente à mudança na vida das famílias com a chegada do PBF. De acordo com os autores, a pesquisa constatou uma evidente transformação na vida das pessoas, que apresentaram uma clara percepção em relação ao antes e depois do programa. Ressalta-se que, embora não se tenha como objetivo realizar comparação de dados referentes à aplicação do Programa Bolsa Família na cidade de Goiatuba com qualquer outra cidade do país, a eficiência dos programas de transferência de renda da cidade de Catingueira apontada pela literatura pode ser usada como referencial para compreensão dessas ações em sua amplitude e a capacidade de produção de efeitos da mesma natureza em regiões diferentes, refletindo positivamente nos indicadores de desenvolvimento.

A pesquisa sobre a experiência do PBF em Catingueira revelou que a vontade de estudar foi amplamente visualizada na geração das mães, mas esse desejo só pôde ser colocado em prática na "Geração Bolsa Família", não pela obrigatoriedade de escolarização imposta como condicionalidades de acesso ao PBF, mas como consequência do recebimento de uma renda familiar regular que, antes, não existia e que consistia em um dos maiores problemas dessas famílias, razão pela qual Pires e Jardim (2014) também defendem que o benefício financeiro seja transformado em um direito universal e incondicional para quem dele necessite. 


\section{Políticas Nacionais de Distribuição de Renda em Goiatuba-GO}

Verifica-se, neste estudo, que o modelo de transferência direta de renda pela atuação do Estado não oferece bens e serviços, mas, no sentido da demanda, a entrega de recursos financeiros com os quais os beneficiários podem prover suas necessidades, ficando a cargo deles o gerenciamento das próprias decisões quanto ao que desejam do mercado. Observa-se, também, que além de menor custo operacional e o efeito multiplicador, a transferência direta de renda permite: gerenciamento de benefícios e beneficiários; autonomia aos beneficiários que são conhecedores de suas próprias necessidades; flexibilidade para a aplicação em diferentes situações de crise social; e adequação ao orçamento.

Esta pesquisa buscou estudar a contribuição das políticas nacionais de distribuição de renda pelo Índice de Desenvolvimento Humano (IDHM) do município de Goiatuba (GO). Caracteriza-se, quanto à abordagem do problema, como qualitativa de tipo documental e bibliográfica; e quanto aos objetivos como descritiva e exploratória, porque não existem estudos para demonstração desse fenômeno no município.

Segundo Brandão (2007), o adequado é que os projetos de Desenvolvimento sejam enfrentados com uma política nacional. $\mathrm{O}$ autor ressalta que a operacionalização ocorre em diferentes escalas espaciais e que é necessário estabelecer uma agenda de debates em relação às estruturas, hierarquias e decisão em uma conjuntura maior, como forma de suprimir os problemas causados pelas políticas de pequena escala. Dallabrida (2013) destaca que a denominação "Desenvolvimento Regional" compreende um amplo processo de mudança que busca alcançar não só resultados econômicos elevados, mas também a melhoria nas condições de vida dos indivíduos de um determinado espaço territorial no que se refere à renda, ao poder aquisitivo, às oportunidades de trabalho e capacitação, às condições de moradia, saúde e lazer, assim como a oportunidade de desfrutar de um ambiente saudável.

O Índice de Desenvolvimento Humano (IDHM) do município de Goiatuba no ano de 2000 foi de 0,628 , enquanto que no ano de 2010 o referido índice passou para 0,725 , conforme dados do PNUD (2013), podendo assim ser constatada uma melhoria do referido indicador que é composto por três diferentes dimensões: renda, longevidade e educação, conforme se observa na Tabela 1.

De acordo com PNUD (2013), o IDHM 0,725 registrado pelo município de Goiatuba em 2010 é considerado alto por estar na faixa entre 0,700 e 0,799, tendo em vista que o índice 
máximo para esse indicador pode chegar até 1,00. A longevidade foi a dimensão que mais contribuiu para a formação do IDHM com índice de 0,825 , sendo seguida pela dimensão de renda com índice de 0,737; e de educação com índice de 0,627. Por sua vez, embora a longevidade tenha sido a dimensão que mais contribuiu para a composição do IDHM obtido em 2000 e 2010, a dimensão em que o índice teve maior crescimento em termos absolutos foi a da educação, que registrou um crescimento de 0,197 , seguida pela renda, com crescimento de 0,026; e por último a longevidade, com 0,016(Tabela 1 ).

Tabela 1 - Taxa de crescimento dos componentes do IDHM - Goiatuba (GO)

\begin{tabular}{l|c|c|r}
\hline & $\mathbf{2 0 0 0}$ & $\mathbf{2 0 1 0}$ & Crescimento \\
\hline IDHM Educação & 0,430 & 0,627 & 0,197 \\
\hline IDHM Longevidade & 0,809 & 0,825 & 0,016 \\
\hline IDHM Renda & 0,711 & 0,737 & 0,026 \\
\hline IDHM Geral & 0,628 & 0,725 & \\
\hline
\end{tabular}

Fonte: adaptada pelo autor, com dados de PNUD (2013).

A melhoria do IDHM de 0,628, em 2000, para 0,725, em 2010, reflete um crescimento de $15,45 \%$. Porém, ao mesmo tempo, houve uma redução em $73,92 \%$ no hiato de desenvolvimento, o que corresponde à distância entre o índice alcançado pelo município de Goiatuba (GO) e o limite máximo do IDHM, conforme a Tabela 2.

Tabela 2 - Hiato de desenvolvimento

\begin{tabular}{lr}
\hline Valor Máximo para o índice IDHM & 1,00 \\
\hline IDHM 2000 & 0,628 \\
\hline IDHM 2010 & 0,725 \\
\hline Taxa de Crescimento do IDHM & $15,45 \%$ \\
\hline Hiato de desenvolvimento 2000 & 0,372 \\
\hline Hiato de desenvolvimento 2010 & 0,275 \\
\hline Redução no Hiato de desenvolvimento & $73,92 \%$ \\
\hline
\end{tabular}

Fonte: adaptada pelo autor do PNUD (2013).

Conforme o PNUD (2013), no ranking de maior IDHM, o município de Goiatuba (GO) ocupa a 1154ạ em relação aos 5.565 municípios brasileiros. São Caetano do Sul (SP) é o município que possui maior IDHM, de 0,86. Melgaço (PA) é o município com menor índice, contando com 0,418. Em relação à população, de acordo com PNUD (2013), viviam no município de Goiatuba um total de 31.130 habitantes no ano de 2000 e 32.492 habitantes em 2010. Houve um crescimento populacional em uma taxa média anual de 0,43\%, enquanto no Brasil a mesma taxa 
foi de $1,17 \%$. Além disso, no mesmo período, a taxa de urbanização do município cresceu de 89,32\% para 92,15\% (Tabela 3).

A Tabela 3 aponta um crescimento populacional do município de Goiatuba em uma taxa média anual muito aquém da mesma taxa de crescimento registrada em âmbito nacional. Os dados colhidos mostram que, no período estudado, houve um aumento da taxa de urbanização.

Tabela 3 - População total, por gênero, rural/urbana de Goiatuba (GO)

\begin{tabular}{l|r|r|r|r}
\hline & População/2000 & $\%$ do Total/2000 & População/2010 & $\%$ do Total/2010 \\
\hline População total & 31.130 & $100,00 \%$ & 32.492 & $100,00 \%$ \\
\hline Homens & 15.549 & $49,95 \%$ & 16.219 & $49,92 \%$ \\
\hline Mulheres & 15.581 & $50,05 \%$ & 16.273 & $50,08 \%$ \\
\hline Urbana & 27.806 & $89,32 \%$ & 29.941 & $92,15 \%$ \\
\hline Rural & 3.324 & $10,68 \%$ & 2.551 & $7,85 \%$ \\
\hline
\end{tabular}

Fonte: adaptada pelo autor do PNUD (2013).

O crescimento populacional não foi proporcional à taxa nacional, o que pode apontar para uma possível privação de oportunidades para o desenvolvimento no meio urbano e mais ainda no meio rural. Quanto à estrutura etária, os dados do PNUD (2013) utilizam uma análise baseada na razão de dependência e na taxa de envelhecimento, demonstrando que entre o ano de 2000 e o ano de 2010 a razão de dependência no município de Goiatuba (GO) foi reduzida de 49,1\% para 45,0\%. Além disso, o índice de envelhecimento subiu de 6,4\% para 8,9\% (Tabela 4).

Tabela 4 - Estrutura etária da população de Goiatuba (GO)

\begin{tabular}{l|r|r|r|r}
\hline Estrutura Etária & População/2000 & $\%$ do Total/2000 & População/2010 & $\%$ do Total/2010 \\
\hline Menos de 15 anos & 8.259 & $26,53 \%$ & 7.203 & $22,17 \%$ \\
\hline 15 a 64 anos & 20.874 & $67,05 \%$ & 22.410 & $68,97 \%$ \\
\hline 65 anos ou mais & 1.997 & $6,42 \%$ & 2.879 & $8,86 \%$ \\
\hline Razão de dependência & $49,13 \%$ & - & $44,99 \%$ & - \\
\hline Índice de envelhecimento & $6,42 \%$ & - & $8,86 \%$ & - \\
\hline
\end{tabular}

Fonte: adaptada pelo autor do PNUD (2013).

De acordo com PNUD (2013), a razão de dependência corresponde ao percentual da população com idade de até 15 anos e, também, com idade superior a 65 anos, ou seja, a população presumidamente dependente em relação à população com idade entre 15 e 64 anos, que é considerada potencialmente ativa. Já a taxa de envelhecimento corresponde à população com idade igual ou superior a 65 anos. Vale observar que, no estado de Goiás, a razão de dependência passou de 54,94\%, em 2000, para 45,92\% em 2010, enquanto a taxa de 
envelhecimento passou de 5,83\% para 7,36\%. A Tabela 5 apresenta o comparativo de dados do município de Goiatuba (GO) referentes à esperança de vida ao nascer (em anos); mortalidade até um ano de idade por mil nascidos vivos; mortalidade até cinco anos de idade por mil nascidos vivos; e taxa de fecundidade total (número de filhos por mulher) entre o ano de 2000 e o de 2010, demonstrando uma melhoria nos referidos indicadores.

Tabela 5 - Longevidade, mortalidade e fecundidade de Goiatuba (GO)

\begin{tabular}{l|r|r}
\hline Esperança de vida ao nascer (em anos) & 2000 & 2010 \\
\hline Mortalidade até 1 ano de idade (por mil nascidos vivos) & 73,5 & 74,5 \\
\hline Mortalidade até 5 anos de idade (por mil nascidos vivos) & 19,7 & 11,0 \\
\hline Taxa de fecundidade total (filhos por mulher) & 23,3 & 13,0 \\
\hline
\end{tabular}

Fonte: PNUD (2013).

Ainda segundo o PNUD (2013), uma das metas do documento "Desenvolvimento do Milênio" das Nações Unidas era exatamente reduzir a mortalidade infantil a índices inferiores a 17,9 por mil nascidos vivos em 2015. Como essa meta já havia sido cumprida pelo Brasil em 2010 com o índice de 16,7, o estado de Goiás e o município de Goiatuba estavam também dentro da meta já no ano de 2010, respectivamente com os índices 14,0 e 11,0 . No que se refere ao resultado das oportunidades de acesso à educação, os dados do PNUD (2013) demonstram que a proporção de crianças e jovens cursando ou já tendo cursado determinados ciclos demonstra o cenário da educação e compõe o IDHM nessa dimensão. No município de Goiatuba (GO), a quantidade de crianças com idade de 5 a 6 anos na escola correspondia a 93,03\% no ano de 2010 . Nesse ano, a proporção de crianças com idade entre 11 e 13 anos frequentando os últimos anos do ensino fundamental foi de 89,72\%; a de jovens com idade de 15 a 17 anos com ensino fundamental completo atingiu 63,43\%; e a de jovens entre 18 a 20 anos com ensino médio completo alcançou $38,60 \%$.

No ano 2000, conforme dados do PNUD (2013), 81,46\% da população do município de Goiatuba (GO) com idade entre seis e 17 anos cursavam o ensino básico regular. Em 2010 houve uma melhoria desse indicador, elevado para $84,65 \%$ com um uma margem de defasagem idade/série de até dois anos. Além disso, entre os jovens adultos com idade entre 18 a 24 anos, em 2000, cursavam o ensino superior 9,99\%. Em 2010 essa taxa subiu para 19,19\%. Outro fato a observar é a expectativa de anos de estudo, indicador que demonstra a frequência escolar da população com idade e série indicadas, apontando especialmente tempo de estudo de uma criança que tenha iniciado a sua vida escolar no ano de referência indicado e que deverá 
completá-la aos 18 anos de idade. Em 2000 esse indicador no município de Goiatuba era de 9,11 e passou em 2010 para 9,82 anos. No estado de Goiás passou de 9,04 para 9,72 anos.

Quanto à educação da população adulta, com 18 anos ou mais e cujos índices também compõem a dimensão educação do IDHM, os dados do PNUD (2013) demonstram que, em Goiatuba, o percentual passou de 33,71\%, no ano 2000 para $48,74 \%$ em 2010 . No estado de Goiás, esse índice passou de 39,76 para 54,92. O Gráfico 1 mostra o cenário da escolaridade da população do município de Goiatuba (GO) com idade igual ou superior a 25 anos no ano de 2000 e de 2010.

Gráfico 1 - Cenário da escolaridade da população do município de Goiatuba (GO) com idade igual ou superior a 25 anos

Escolaridade da populaçăo de 25 anos ou mais - 2000

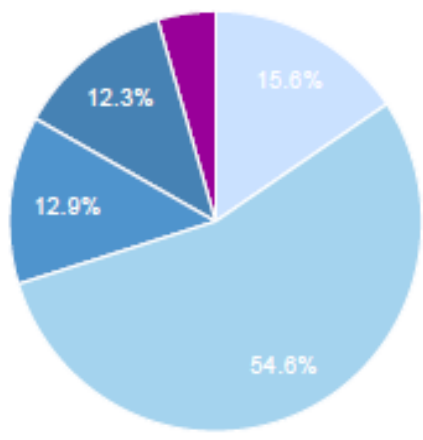

Escolaridade da população de 25 anos ou mais - 2010

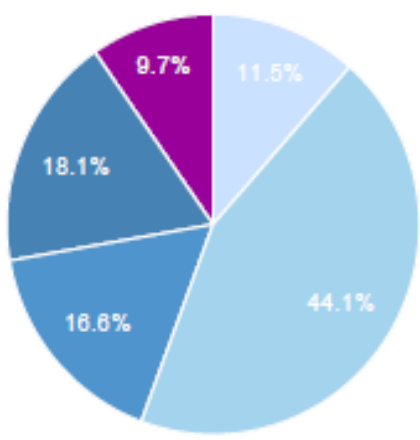

Fonte: PNUD (2013).

A renda é um importante indicador a ser observado na composição do IDHM. Conforme dados do PNUD (2013), no município de Goiatuba (GO), a renda per capita média era de R\$ 667,28 em 2000 e passou para $\mathrm{R} \$ 785,84$ em 2010. Esse crescimento compreendeu uma taxa média anual de 1,65\% entre 2000 e 2010 . A Tabela 6 mostra o comparativo dos dados de 2000 e 2010 referentes à renda per capita, à porcentagem de pessoas pobres, extremamente pobres e o Índice de Gini.

Tabela 6 - Renda, Pobreza e Desigualdade de Goiatuba (GO)

\begin{tabular}{l|r|r}
\hline & 2000 & 2010 \\
\hline Renda per capita (em R\$) & 667,28 & 785,84 \\
\hline \% de extremamente pobres & 4,90 & 1,18 \\
\hline \% de pobres & 16,23 & 3,98 \\
\hline Índice de Gini & 0,65 & 0,50 \\
\hline
\end{tabular}

Fonte: PNUD (2013). 
Registrou-se também redução na proporção de pessoas pobres, assim consideradas aquelas cuja renda per capita familiar em agosto de 2010 era inferior a $\mathrm{R} \$ 140,00$. Conforme o PNUD (2013), a proporção de pessoas pobres passou de 16,23\% em 2000 para 3,98\% em 2010. Dessa forma, fica demonstrada uma evolução no que se refere à desigualdade de renda descrita pelo índice de Gini, que passou de 0,65 em 2000 para 0,50 em 2010. A Tabela 7 demonstra que, de acordo com os dados do PNUD (2013) entre a população de 18 anos ou mais, houve melhoria na taxa de atividade, passando de $65,46 \%$ no ano de 2000 para $69,12 \%$ no ano de 2010 . Essa taxa corresponde à parcela da população com idade igual ou superior a 18 anos economicamente ativa e ocupada.

Tabela 7 - Ocupação da população de 18 anos ou mais de Goiatuba (GO)

\begin{tabular}{l|r|r}
\hline Taxa de atividade (população economicamente ativa e ocupada) & 2000 & 2010 \\
\hline Taxa de desocupação (população economicamente ativa e desocupada) & 65,46 & 69,12 \\
\hline Taxa de inatividade (população economicamente inativa) & 28,14 & 4,78 \\
\hline Grau de formalização dos ocupados & 41,49 & 26,10 \\
\hline
\end{tabular}

Nível educacional dos ocupados

\begin{tabular}{l|r|r}
\hline \% dos ocupados com fundamental completo & 40,36 & 55,78 \\
\hline \% dos ocupados com médio completo & 23,53 & 36,25 \\
\hline
\end{tabular}

\section{Rendimento médio}

\% dos ocupados com rendimento de até 1 s.m.

$\%$ dos ocupados com rendimento de até 2 s.m.

Percentual dos ocupados com rendimento de até 5 salários mínimo

Fonte: adaptada pelo autor do PNUD (2013).

Além disso, observa-se pelos dados do PNUD (2013) constantes da Tabela 7 que o município de Goiatuba (GO) registrou uma redução na taxa de desocupação de 6,40\%, no ano de 2004, para 4,78\%, em 2010. Essa taxa corresponde à parcela da população com idade igual ou superior a 18 anos economicamente ativa e desocupada. Os dados do PNUD (2013) da referida tabela demonstram também outro ponto positivo do município de Goiatuba (GO), que é a taxa de inatividade referente à parcela da população com idade igual ou superior a 18 anos economicamente inativa, que passou de $28,14 \%$ no ano de 2000 para $26,10 \%$ em 2010.

Houve melhoria nos indicadores de habitação do município de Goiatuba (GO). No que se refere à porcentagem dos domicílios que têm água encanada houve aumento do ano 2000 
para 2010 , respectivamente, de 94,51\% para 97,62\%. Com relação à energia elétrica, o aumento passou de 99,04\% em 2000 para 99,48\% em 2010 e, com a coleta de lixo, considerando apenas a população urbana, o índice passou de 97,91\% em 2000 para 99,01\% em 2010, o que pode ser mais bem visualizado na Tabela 8 .

Tabela 8 - Indicadores de habitação de Goiatuba (GO)

\begin{tabular}{l|r|r}
\hline & 2000 & 2010 \\
\hline \% da população em domićílios com água encanada & 94,51 & 97,62 \\
\hline \% da população em domićlios com energia elétrica & 99,04 & 99,48 \\
\hline \% da população em domićlís com coleta de lixo. & & \\
*Somente para população urbana. & 97,91 & 99,01 \\
\hline
\end{tabular}

Fonte: PNUD (2013).

Os dados do PNUD (2013) apresentados no Tabela 9 demonstram que do ano 2000 para 2010 houve melhoria nos índices utilizados para observação da vulnerabilidade social no município de Goiatuba (GO).

Tabela 9 - Vulnerabilidade social - Goiatuba (GO)

\begin{tabular}{l|r|r}
\hline Crianças e Jovens & 2000 & 2010 \\
\hline Mortalidade infantil & 19,70 & 10,98 \\
\hline \% de crianças de 0 a 5 anos fora da escola & 86,23 & 62,00 \\
\hline \% de crianças de 6 a 14 fora da escola & 4,71 & 3,07 \\
\hline $\begin{array}{l}\text { \% de pessoas de 15 a 24 anos que não estudam, não trabalham e são } \\
\text { vulneráveis, na população dessa faixa. }\end{array}$ & 14,36 & 6,18 \\
\hline \% de mulheres de 10 a 17 anos que tiveram filhos & 3,44 & 3,21 \\
\hline Taxa de atividade - 10 a 14 anos & 16,26 & 16,86 \\
\hline & & \\
\hline Família & & \\
\hline $\begin{array}{l}\text { \% de mães chefes de família sem fundamental e com filho menor, no total } \\
\text { de mães chefes de família. }\end{array}$ & 11,38 & 8,29 \\
\hline \% de vulneráveis e dependentes de idosos & 3,65 & 1,64 \\
\hline $\begin{array}{l}\text { \% de crianças com até 14 anos de idade que têm renda domiciliar per } \\
\text { capita igualou inferior a R\$̦ 70,00 mensais }\end{array}$ & 7,83 & 1,85 \\
\hline & & \\
\hline $\begin{array}{l}\text { Trabalho e Renda } \\
\text { \% de vulneráveis à pobreza }\end{array}$ & & \\
\hline $\begin{array}{l}\text { \% de pessoas de 18 anos ou mais sem fundamental completo e em } \\
\text { ocupação informal }\end{array}$ & 55,08 & 19,32 \\
\hline & 54,84 & 39,52 \\
\hline Condição de Moradia & & \\
\hline \% da população em domicílios com banheiro e água encanada & 92,45 & 94,12 \\
\hline
\end{tabular}

Fonte: PNUD (2013). 
Conforme os dados da Tabela 9 referentes à observação da vulnerabilidade social no município de Goiatuba (GO) houve uma redução significativa nas taxas: i) de mortalidade de crianças de zero a cinco anos, e de seis a 14 fora da escola; ii) de pessoas vulneráveis de 15 a 24 anos que não trabalham e não estudam; e iii) de mulheres de 10 a 17 anos que tiveram filhos, embora tenha sido observado um aumento na taxa de atividade das crianças de 10 a 14 anos, que passou de 16,26 em 2000 para 16,86 em 2010, o que pode indicar a existência de trabalho infantil. Além disso, observou-se também, entre 2000 e 2010, uma expressiva redução nas taxas referentes à família: de mães chefes de família sem o ensino fundamental com filho menor de idade; de vulneráveis e dependentes de idosos; de crianças com até 14 anos com renda domiciliar per capita igual ou inferior a $\mathrm{R} \$ 70,00$. No que se refere à renda e ao trabalho houve no mesmo período uma redução na taxa de vulneráveis à pobreza e de pessoas de 18 anos ou mais sem o ensino fundamental completo e em situação ocupacional informal. Registrou-se ainda uma melhoria no que se refere às condições de moradia com aumento na taxa da população em domicílios com banheiro e água encanada.

O Gráfico 2 demonstra a evolução da quantidade de famílias inscritas no Cadastro Único para Programas Sociais (Cadúnico) de Goiatuba, com renda familiar per capita de até $1 / 2$ salário mínimo, tendo subido da casa de 2.200 a 2.400 pessoas inscritas em 2007 para 2.800 em 2010, demonstrando que o cadastro estava em plena operacionalidade no município no mencionado período.

Gráfico 2 - Evolução da quantidade de famílias inscritas no Cadastro Único para programas sociais

3.000

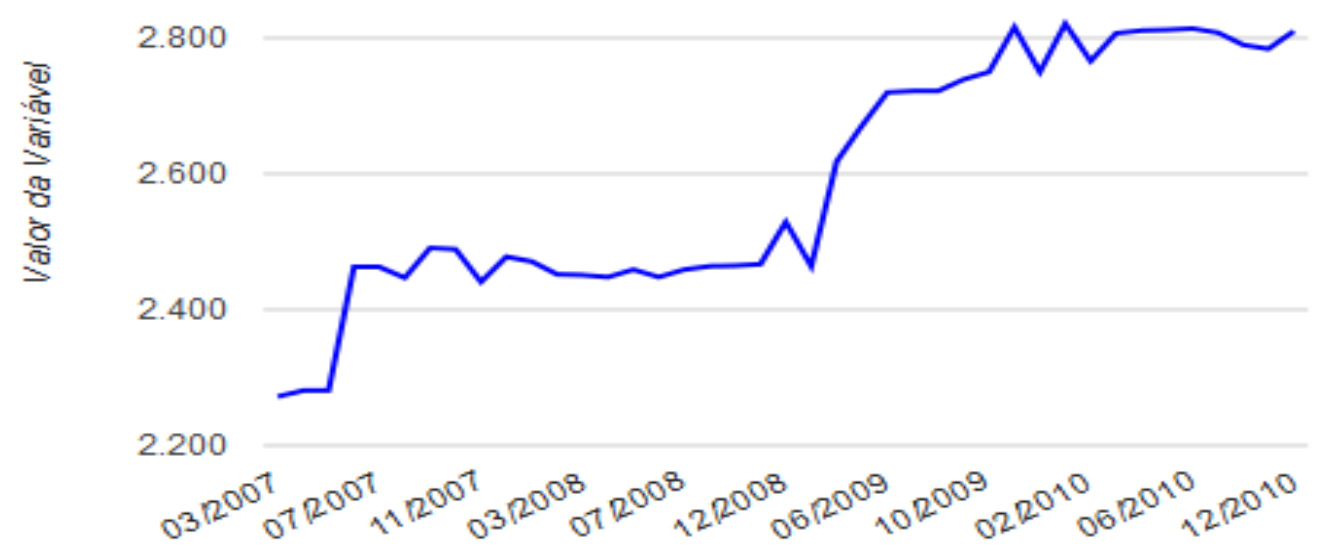

Fonte: MDS. 
O Gráfico 3 apresenta a evolução do benefício médio mensal por família do Programa Bolsa Família, demonstrando que entre 2004 e 2007 houve uma queda no valor médio mensal. Porém, entre 2007 e 2010, o valor mensal por família teve uma evolução significativa, o que pode demonstrar maior grau de focalização do programa, o seu nível de eficiência, conforme conceitua Barros et al (2010).

Gráfico 3 - Evolução do benefício médio mensal por família do Programa Bolsa Família 110
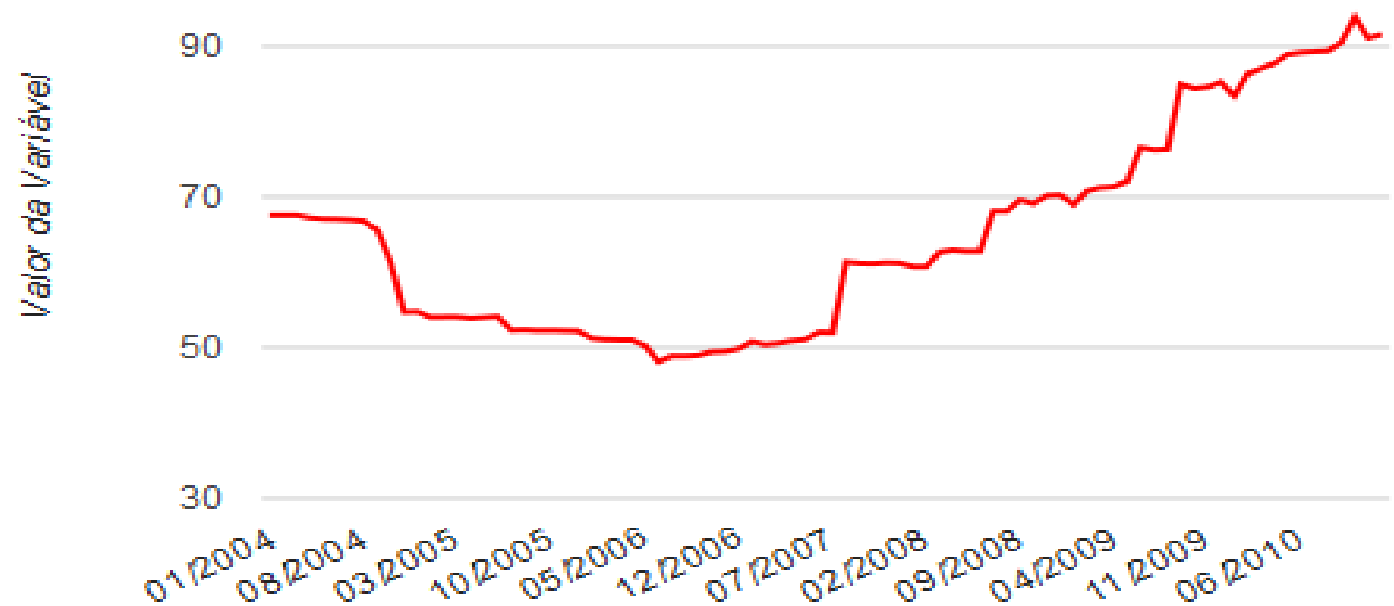

Fonte: MDS.

O Gráfico 4 aponta uma evolução do valor total repassado pelo programa Bolsa Família ao município de Goiatuba (GO), saindo da casa dos R\$ 50.000 no início de sua execução em 2004 para superar $\mathrm{R} \$ \mathbf{1 5 0 . 0 0 0 , 0 0}$ em 2010, atendendo às finalidades específicas do Programa no sentido de promover a superação do estado de pobreza e de extrema pobreza das famílias beneficiárias, mas contribuindo também com o fomento da economia local em um efeito multiplicador.

Gráfico 4 - Evolução do valor total repassado do Programa Bolsa Família 


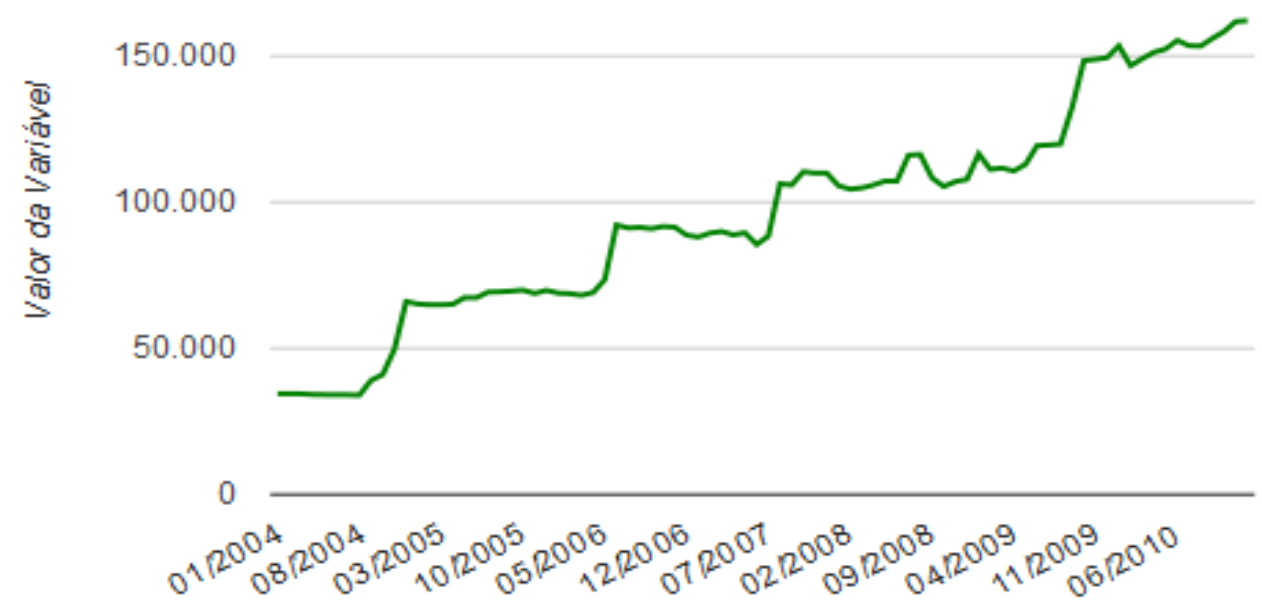

Fonte: MDS.

Conforme comparativo dos indicadores de desenvolvimento do município de Goiatuba (GO), no período de 2000 a 2010 houve avanço em todas as dimensões que compõem o Índice de Desenvolvimento Humano (IDHM). Possivelmente contribuiu com esse resultado o importante cenário de políticas públicas voltadas à melhoria desses índices, destacando-se os programas de distribuição direta de renda, em especial o Benefício de Prestação Continuada e o Programa Bolsa Família.

\section{Considerações finais}

O aumento da renda familiar e a consequente redução da pobreza podem apresentar efeitos positivos para o crescimento econômico e o desenvolvimento regional, bem como efeitos diretos na qualidade da alimentação e melhor distribuição do tempo dos membros familiar entre o trabalho, a educação e o lazer, possibilitando medidas de proteção às crianças.

O objetivo deste artigo justifica-se tendo em vista a confirmação de que as políticas de transferência de renda podem contribuir para a melhoria das condições de vida dos beneficiários não apenas na dimensão renda, mas também em outras dimensões sociais, como a longevidade e a educação, muito em razão de suas condicionalidades. Essas políticas são ainda importantes fomentadoras da economia local de pequenos municípios, como é o caso de Goiatuba (GO), que teve grandes avanços em seus indicadores de desenvolvimento entre 2000 e 2010. A literatura demonstrou que as condicionalidades do programa Bolsa Família recebem críticas a partir da consideração de que deveriam ser impostas ao Estado e não ao beneficiário, mas são defendidas 
como indispensáveis na quebra do ciclo de pobreza que tende a se reproduzir entre gerações. Nesse sentido, o Bolsa Família apresenta potencial para contribuir com a inclusão das famílias assistidas no processo de desenvolvimento.

Os indicadores de desenvolvimento do município de Goiatuba (GO) apresentaram significativa melhoria no período de 2000 a 2010 em todas as dimensões que compõem o Índice de Desenvolvimento Humano (IDHM), valendo ressaltar que esses indicadores, já em 2010, alcançaram inclusive metas mundiais previstas para serem alcançadas até 2015.

Acredita-se que as políticas de transferência de renda tenham contribuído com os resultados positivos obtidos no município de Goiatuba. Esse avanço, registrado na última década, das políticas públicas voltadas à melhoria desses índices, destacando-se os programas de distribuição direta de renda ao beneficiário, em especial o Benefício de Prestação Continuada e o Programa Bolsa Família, evidenciam que os dois Programas têm a capacidade de refletir positivamente no acesso aos Direitos de Cidadania e ao desenvolvimento da família beneficiada, com efeito multiplicador na sua região. A delimitação mais precisa das condições de inclusão social e econômica propiciada com os programas de transferência de renda requer pesquisas dedicadas a interlocução direta com os beneficiários, o que pode ser objeto de futuras investigações com o propósito de elaborar estratégias para a continuidade do avanço constatado nesse artigo.

\section{Referências}

ABRAMOVAY, Ricardo. Para uma teoria dos estudos territoriais. In: VIEIRA, Paulo F. et al. (Org.). Desenvolvimento territorial sustentável no Brasil. Florianópolis: Aped; Secco, 2010.

BARROS, Ricardo P. et al. A focalização do programa bolsa familia em perspectiva comparada. In: CASTRO, Jorge A. e MODESTO, L. (Organizadores). Bolsa Família 2003-2010: Avanços e desafios. Brasília: Ipea, 2010.

BIM, Miriam Cláudia Spada; MUROFUSE, Neide Tiemi. Benefício de Prestação Continuada e perícia médica previdenciária: limitações do processo. Serv. Soc. Soc. São Paulo, n. 118, p. 339365, June 2014. Disponível em:

http://www.scielo.br/scielo.php?script=sci arttext\&pid=S010166282014000200007\&lng=en\&nrm=iso. Acesso em: 07/01/2016.

BRASIL. Constituição da República Federativa do Brasil de 1988. Diário Oficial da União, Brasília, DF, 5 out. 1988. Disponível em: http://www.planalto.gov.br/ccivil 03/constituicao/cons tituicao.htm. Acesso em: 27/04/2015. 
BRASIL. Lei $n^{\circ}$ 8.742, de 7 de dezembro de 1993. Dispõe sobre a organização da Assistência Social e dá outras providências. Diário Oficial da União, Brasília, DF, 7 Dez. 1993. Disponível em: http://www.planalto.gov.br/ccivil 03/leis/L8742.htm. Acesso em: 11/04/2017.

BRASIL. Lei $n^{\circ}$ 10.836, de 9 de janeiro de 2004. Cria o Programa Bolsa Família e dá outras providências. Diário Oficial da União, Brasília, DF, 12 Jan. 2004. Disponível em:

http://www.planalto.gov.br/ccivil 03/ ato2004-2006/2004/lei/l10.836.htm. Acesso em: 13/05/2015.

BRASIL. Medida Provisória no 132, de 20 de outubro 2003. Cria o Programa Bolsa Família e dá outras providências. Diário Oficial da União, Brasília, DF, 21/10/2003.

BRANDÃO, Carlos. A busca da utopia do planejamento regional. Revista Paranaense de Desenvolvimento, Curitiba, n. 120, p. 17-37, 2011.

Carlos. Território e desenvolvimento: as múltiplas escalas entre o local e o global. Campinas: Editora da Unicamp, 2007.

BUARQUE, C.S. Construindo o desenvolvimento local sustentável. São Paulo: Garamond, 2006.

CACCIAMALI, Maria Cristina; TATEI, Fábio; BATISTA, Natália Ferreira. Impactos do Programa Bolsa Família federal sobre o trabalho infantil e a frequência escolar. Rev. econ. contemp., Rio de Janeiro, v. 14, n. 2, p. 269-301, Ago. 2010. Disponível em: http://www.scielo.br/scielo.php?script=sci arttext\&pid=S141598482010000200003\&lng=en\&nrm=iso. Acesso em: 13/05/2015.

COSTA, F. L.; CUNHA, A.P.G. Pensar o desenvolvimento a partir do local: novo desafio para os gestores públicos. CONGRESSO INTERNACIONAL DEL CLAD SOBRE LA REFORMA DEL ESTADO Y DE LA ADMINISTRACIÓN PÚBLICA, 7. 2002, Lisboa. Anais. Lisboa: Centro Latino-americano de Administración para el Desarrollo, 2002.

DALLABRIDA, Valdir Roque. Desenvolvimento territorial: políticas públicas brasileiras, experiências internacionais e a indicação geográfica como referência. 1. Ed. São Paulo: LiberArs, 2014.

Valdir Roque. Território, identidade territorial e desenvolvimento regional.

Reflexões sobre indicação geográfica e novas possibilidades de desenvolvimento com base em ativos com especificidade territorial. São Paulo: LiberArs, 2013.

FERREIRA, H.V.C. Programa de desenvolvimento integrado e sustentável de mesorregiões: uma experiência inovadora de desenvolvimento regional do governo brasileiro. CONGRESSO INTERNACIONAL DEL CLAD SOBRE LA REFORMA DEL ESTADO Y DE LA ADMINISTRACIÓN PÚBLICA, 7. 2002, Lisboa. Anais. Lisboa: Centro Latino-americano de Administración para el Desarrollo, 2002.

GRANITO, Roberta Aparecida Neves et al. Desenvolvimento regional e novos paradigmas: iniciativas de promoção do desenvolvimento na comunidade da Mangueira. Cad. EBAPE.BR, Rio de Janeiro, v. 5, n. 2, June 2007. Disponível em: http://www.scielo.br/scielo.php? script=sci_arttext\&pid=S1679-39512007000200006\&lng=en \&nrm=iso. Acesso em: 27/08/2015. MEDEIROS, Marcelo; BRITTO, Tatiana; SOARES, Fábio. Transferência de renda no Brasil. Novos estudos - CEBRAP, São Paulo, n. 79, p. 5-21, Nov. 2007. Disponível em:

http://www.scielo.br/scielo.php?script=sci arttext\&pid=S010133002007000300001\&lng=en\&nrm=iso. Acesso em: 03/01/2016. 
MDS (BR). MINISTÉRIO DO DESENVOLVIMENTO SOCIAL E COMBATE À FOME. Bolsa Família. 2015. Disponível em: http://www.mds.gov.br/bolsafamilia. Acesso em: 13/05/2015.

OLIVEIRA, Gilson Batista de; LIMA, JE de S. Elementos endógenos do desenvolvimento regional: considerações sobre o papel da sociedade local no processo de desenvolvimento sustentável.

Revista da FAE, Curitiba, v. 6, n. 2, p. 29-37, 2003. Disponível em: http://scholar. googleusercontent.com/scholar?q=cache:MBQaZt6REQoJ:scholar.google.com/\&hl=ptBR\&as sdt $=0,5$. Acesso em: 27/08/2015.

PAES, Nelson Leitão; SIQUEIRA, Marcelo Lettieri. Desenvolvimento regional e federalismo fiscal no Brasil: em busca da igualdade na distribuição de receitas. Econ. Apl., Ribeirão Preto, v. 12, n. 4, Dec. 2008. Disponível em: http://www.scielo.br/scielo.php?script=sci_arttext \&pid=S1413$\underline{80502008000400008 \& \operatorname{lng}=e n \& n r m=i s o}$. Acesso em: 16/02/2015.

PIRES, Flávia Ferreira; JARDIM, George Ardilles da Silva. Geração bolsa família escolarização, trabalho infantil e consumo na casa sertaneja (Catingueira/PB). Rev. bras. Ci. Soc., São Paulo. v. 29, n. 85, p. 99-112, Jun 2014. Disponível em: http://www.scielo.br/scielo.php?script =sci arttext\&pid=S0102-69092014000200007\&lng=en\&nr m=iso. Acesso em 16/05/2015.

SANTOS, Milton. A natureza do espaço: técnica e tempo, razão e emoção. 4. Ed. São Paulo: Editora da Universidade de São Paulo, 2006.

SEN, A. Desenvolvimento como Liberdade. Tradução de Laura Teixeira Motta. São Paulo: Companhia de Bolso, 2010.

VAITSMAN, Jeni; ANDRADE, Gabriela Rieveres Borges de; FARIAS, Luis Otávio. Proteção social no Brasil: o que mudou na assistência social após a Constituição de 1988. Ciênc. saúde coletiva, Rio de Janeiro, v. 14, n. 3, p. 731-741, June 2009. Disponível em:

http://www.scielosp.org/scielo.php?script=sci arttext\&pid=S141381232009000300009\&lng=en\&nrm=iso. Acesso em: 07/01/2016.

VIEIRA, E. T. \& SANTOS, M. J. Desenvolvimento econômico regional - uma revisão histórica e teórica. Revista Brasileira de Gestão e Desenvolvimento Regional. v. 8, n. 2, p. 344 - 369, mai ago/2012, Taubaté, SP, Brasil. Disponível em:

http://www.rbgdr.net/revista/index.php/rbgdr/article/view/679. Acesso em 07/01/2016.

ZIMMERMANN, Clóvis Roberto. Os programas sociais sob a ótica dos direitos humanos: o caso do Bolsa Família do governo Lula no Brasil. Sur, Rev. int. direitos human., São Paulo, v. 3, n. 4, p. 144-159, Jun 2006. Disponível em: http://www.scielo.br/scielo.php?script=sci arttext\& pid=S1806-64452006000100009\&lng=en\&nrm=iso. Acesso em 16/05/2015. 